抄 錄

\section{一帮 銅-}

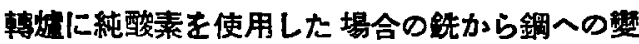

化 Eleinrich Helbrügge: Stahl u. Eiseu (1950) 70, No 26., 1208/11)

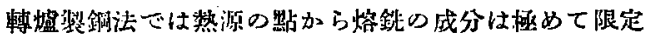

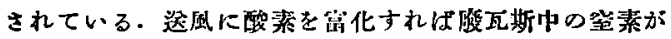
持去る䱈望を減少し得て熔跌成分の制限は㱠んど除かれ

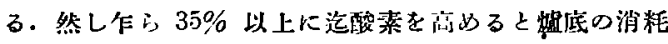

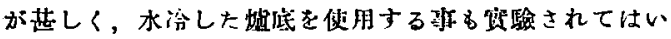

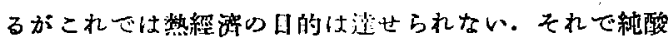
素を用いよ5とすれ代来心底吹と作用し酸素を上から 吹きつける他はない。

スイス・ゲルラアフインゲンの L. vơn Rollschen Eisenwerk こは R. Durrer の指望を受け 2.5t の小轉

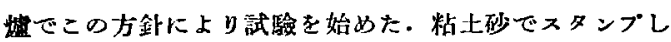

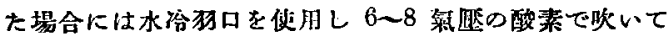

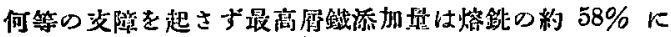

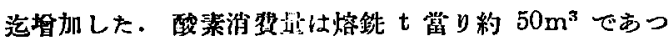
た、タールドロマイトでスタンブした嘘では邪口上部の

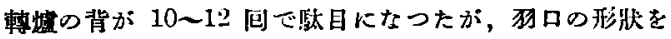

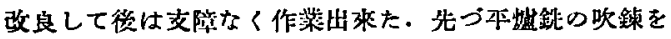

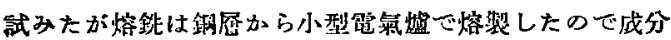

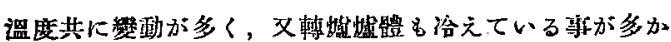
つたので一定の結果は得られなかつた．更に燐琙を用い トーマス銑を揢製吹铢したがこの場合には序理添加量

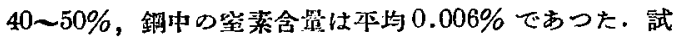

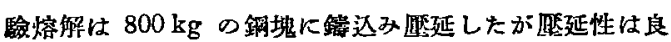

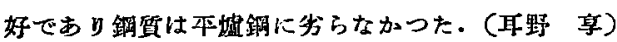

\section{溶鐵と $\mathrm{FeO}$ 低湿慶のスラッグ間の $\mathrm{S}$ の分配}

R. Rocca, N. J. Grant, J. Chipmam: J. of Metals 3 (1951) 4. 319

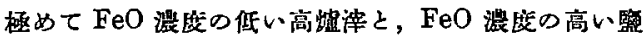

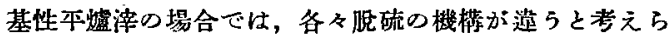
れるが，こャでは $\mathrm{FeO}$ の澴度から云つて，雨者の中間

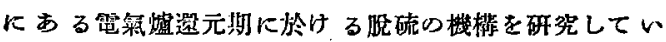
る.

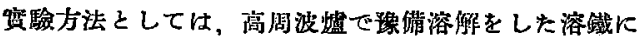
FeS 及び Si を添加し，そに合成スラッグを投入して約 30 分後，本衡に遘してからサンプルを探集して分析を。
行つている.この埸合の投入スラッグの $\mathrm{FeO}$ 漫度は

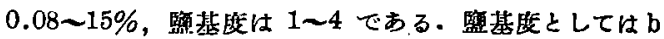
$=(\mathrm{CaO})+(\mathrm{MgO}) /\left(\mathrm{SiO}_{2}\right)+\left(\mathrm{Al}_{2} \mathrm{O}_{3}\right)$ をと, $\mathrm{b}>\mathrm{I}$ を篮 基性， $\mathrm{b}<1$ を酸珄スラッグとして取报つた。結果の考

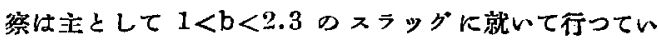
る.

すへてての $\mathrm{FeO}$ 灌度に亘つて，煳硫は次の反墌を基に

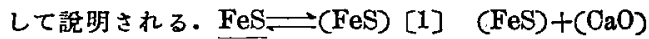
$\rightleftarrows(\mathrm{CaS})+(\mathrm{FeO})[2] \quad \mathrm{FeS}+(\mathrm{CaO}) \rightleftarrows(\mathrm{CaS})+$

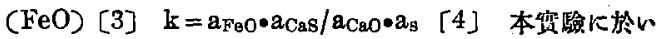

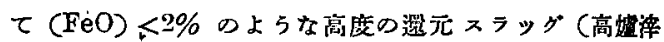
む同桹)では，质硫は主として[2]，式によつて支配さ

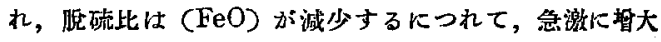
するＦeO をこれより多く含有しているスラッグでは，

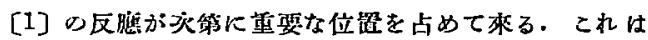
( $\mathrm{FeO}$ ) が掼加するにつれて (CaS) が急激に隇少するか らである. 更に $(\mathrm{FeO})>10 \%$ になると.(CaS) は全く 無悓できて，[1]式の分配のみが，支配因子となる。斯

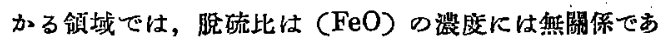
る.

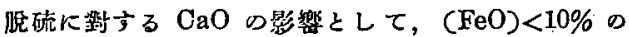
スラッグに龆しては、Grant の方法に上つで計算きれ る “excess $\mathrm{CaO} ”$ の值も文，(FeO）の濃度と並んで支

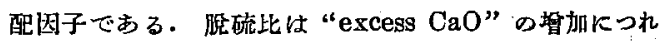
て，大きくなる。

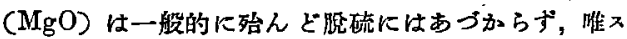
ラッグの監基度を高めると云ら點で，間接的に奇與する のみである。

更に以上の考察は全く分子論的な立場からなされたも・ のであるが，1オン性溶液の見地から二、三の現象を說 明している。(坂上 六郎)

炭素飽和鐵と $\mathrm{CaO}-\mathrm{SiO}_{2}-\mathrm{Al}_{2} \mathrm{O}_{3}$ 系スラッダの 間における S の移動の機構， G. Derge, W.o. Philbrook and Kenneth M. Goldman; J. Metals, 188 (1950) No. 8. 11

㧤硫反膲の速度を支配する因子が如何なるるのである かを知ることは實際上大切な問題であつて，このために

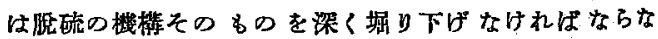

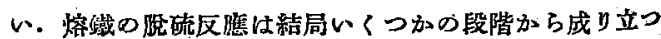
ているものであつて; 今までこれらの段階について脚 
的な考察は加えられていたが神湅な定盘的な设驗は始ん

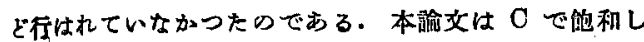

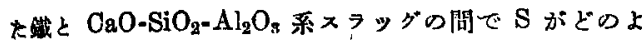

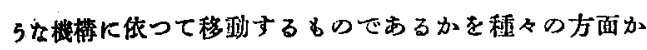
ら考察したるのである。

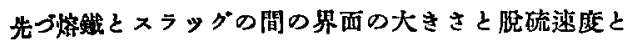
の㽗俰を調へるために先に Chang 及び Goldman の行

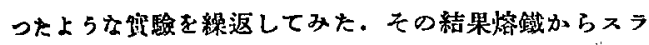

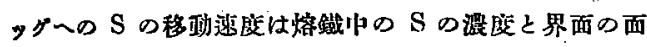

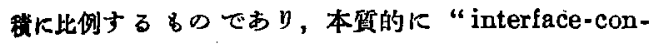
trolled reaction”であることが磼められた。

スラッグ中の S 及び Fe の茼度が時間と共に则何に 警化してゆくすのであるかを調でてみたＳの湠店は初 めは急に大きくなるが夲第人或る定常傎に近ついてい く、F゙は初期に括いては が或る時間で最大に等つてての後は少し娍少する上5な

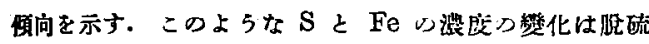
反怔が $\mathrm{S}$ と共K $\mathrm{Fe}$ が䔟動することに依つて行はれる ชのであるととを示している。

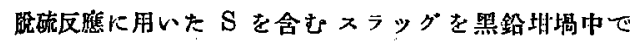
再揢蝟すると $\mathrm{Fe}$ の小洐が生成されるが, $\mathrm{BeO}, \mathrm{SiO}_{2}$,

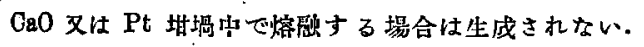
又 00 ガスの發生が認められ，ての發生量は溫度の高

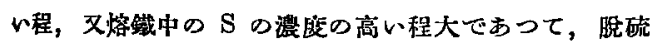
反隼と開保あることが喑示される。

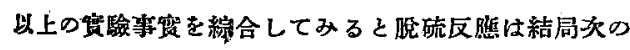
三つの段階から成り立つていることが結諭される。

1. $\mathrm{FeS}_{(\mathrm{Fe})} \rightleftarrows \mathrm{FeS}_{\text {(slag) }}$

2, $\mathrm{FeS}_{(\text {slag) }}+\mathrm{CaO}_{\text {(slag) }} \rightleftarrows \mathrm{CaS}_{\text {slag }}+\mathrm{FeO}_{\text {(slag) }}$

3. $\mathrm{Fe} 0_{(\mathrm{slag})}+\mathrm{C} \longrightarrow \mathrm{Fe}+\mathrm{CO}_{\text {(gas) }}$ (森 一美)

溶鐵中のパナヂウムー酸素平衡

J. Chipman \& M. N. Dástur: Journal of Metals 191 (1951) 2. 111

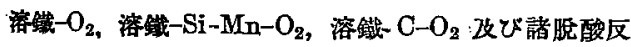
應につレて数多くの交嗝をあげ, Chen 及び Ohipman К上る溶鐵中の $\mathrm{O}_{2}$ 活最に改压す $\mathrm{Cr}$ の影響の研究を引

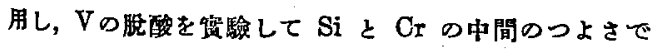
あり, $\mathrm{V}$ \& $\mathrm{O}_{2}$ の間に一方がたかくてを他方の垡留子

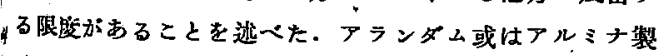

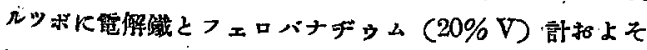
$70 \mathrm{~g} x$ をと加し, $1600^{\circ} \mathrm{C}$ に於て, 水素, 水蒸重の混合冢 を流した、酸生成物を、 $\mathrm{X}$ 線前方反身で調でて，V> $0.35 \%$ の㭙忙 $\mathrm{V}_{2} \mathrm{O}_{3}, \mathrm{~V}=0.10 \%$ の哖K $\mathrm{FeV}_{2} \mathrm{O}_{4}$ とを め.

$$
\begin{array}{r}
\mathrm{H}_{2}(\mathrm{~g})+\underline{\mathrm{O}}=\mathrm{H}_{2} \mathrm{O}(\mathrm{g}) \\
\mathrm{K}_{1}=\mathrm{p}_{\mathrm{H}_{2}} / \mathrm{p}_{\mathrm{H}_{2}} \cdot \mathrm{a}_{0}
\end{array}
$$

この式の $1600^{\circ} \mathrm{C}$ に拈ける $\mathrm{K}_{1}=3.95$ であるから， Henry 則を假定して $V$ 存在に指ける $f_{0}$ (酸素の活最 保㪄を求めることができる， $\log \mathrm{f}_{0}-\mathrm{V} \%$ は值線にな

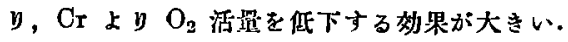

$$
\begin{aligned}
& \mathrm{V}_{2} \mathrm{O}_{3}(\mathrm{~s})+3 \mathrm{H}_{2}(\mathrm{~g})=2 \mathrm{~V}+3 \mathrm{H}_{2} \mathrm{O}(\mathrm{g}) \ldots \ldots \ldots \ldots \ldots \\
& \mathrm{FeV}_{2} \mathrm{O}_{4}(\mathrm{~s})+4 \mathrm{H}_{2}(\mathrm{~g})=2 \underline{\mathrm{V}}+4 \mathrm{H}_{2} \mathrm{O}(\mathrm{g})+\mathrm{Fe}(\mathrm{I})
\end{aligned}
$$

このニ式と（1）を組合せて

$$
2 \underline{\mathrm{V}}+3 \underline{\mathrm{Q}}=\mathrm{V}_{2} \mathrm{O}_{3}(\mathrm{~s}) \quad \Delta \mathrm{F}^{\circ}=-49,300 \mathrm{cal} . \ldots . .(4)
$$$$
\mathrm{Fe}(\mathrm{I})+2 \underline{\mathrm{V}}+4 \underline{\mathrm{Q}}=\mathrm{FeV}_{2} \mathrm{O}_{4}(\mathrm{~s})
$$$$
\Delta \mathrm{F}^{\circ}=-61,200 \mathrm{cal}
$$

次に交擜加ら， $2 \mathrm{~V}(\mathrm{~s})+3 / 2 \mathrm{O}_{2}(\mathrm{~g})=\mathrm{V}_{2} \mathrm{O}_{3}(\mathrm{~s})$ の自由工

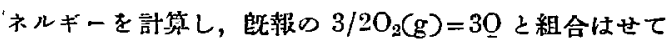

$$
\begin{aligned}
& 2 \mathrm{~V}(\mathrm{~s})+3 \underline{\mathrm{O}}=\mathrm{V}_{2} \mathrm{O}_{2}(\mathrm{~s}) \\
& \Delta \mathrm{F}^{\circ}\left(1600^{\circ} \mathrm{C}\right)=-98,800 \mathrm{cal} \text {. } \\
& \text { こD(4), (6) ゅ二式から } \\
& \mathrm{V}(\mathrm{s})=\underline{\mathrm{V}} \quad \Delta \mathrm{F}^{\circ}\left(1600^{\circ} \mathrm{C}\right)=-24,700 \mathrm{cal} \ldots \ldots(7)
\end{aligned}
$$

一方この (7) の. $\Delta \mathrm{F}^{\circ}$ を訫算から見程ると $-16,700$ cal となるから,この美の $-8,000 \mathrm{cal}$ は $\mathrm{Fe}-\mathrm{V}$ 溶液が Ranolt 則加らふるる程应を表はし，RT $\ln \gamma^{\circ}$ に等しく おいて $r(\mathrm{~V}$ の活盐保数 $)=0.12$ をなるが，0.25より小 さい上将えるのが安全である・從つて

$V(s)=\underline{V} \quad \Delta F^{\circ}=-3,900-11.1 T$.

のよ5に溫度函数が求められる。これから

$$
\begin{aligned}
& \mathrm{V}_{2} \mathrm{O}_{3}=2 \underline{\mathrm{V}}+3 \underline{\mathrm{O}} \\
& \Delta \mathrm{F}^{\circ}=195,900-78.2 \mathrm{~T} \\
& \log \mathrm{K}=-42,800 / \mathrm{T}+17.10
\end{aligned}
$$

○は少すいから V 活是に及汪子影帮を無視して\%V

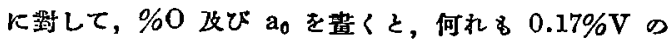
附近で折れる直線双は曲線になり，その前牛改び後牛が $\mathrm{V}_{2} \mathrm{O}_{3}$ と $\mathrm{FeV}_{2} \mathrm{O}_{3}$ に相賞するおけである。

\section{(松下 垶雄)}

冶金スラッグとその反應 E. Eyt； Les Laitiers Métallurgiques at Leurs Réactions (1949) Dunod, Paris

本書は著者の學位諭交として執筆されたるので，約 100 頁の小册子，全體が三部に分れて括り，第一部は二

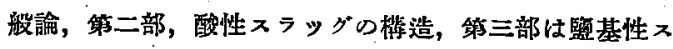
ラッグの㯇造となつている・こではその各々に就いて 抄錄をとつた。

$$
\text { 第一部，一般論 }
$$




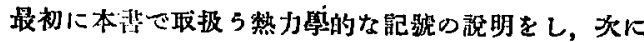

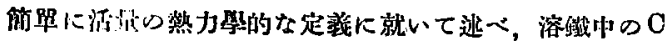

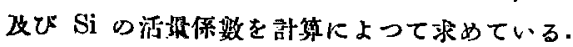

(I) 溶鐵中の 0 の活题保数

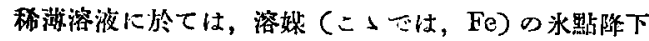

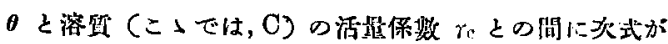
成立する。

$$
\begin{aligned}
& \log \gamma c=\int_{0}^{\mathrm{m}}-\mathrm{jd}(\log \mathrm{m})-\mathrm{j}+\int_{u}^{\mathrm{m}} \mathrm{Z} \theta \frac{\mathrm{d} \theta}{\mathrm{m}} \quad \cdots \cdots(1) \\
& \mathrm{B}=1 / \mathrm{R} \Theta^{2} \cdot\left(\begin{array}{c}
\mathrm{L}_{0} \\
\Theta
\end{array}-\frac{\Delta \mathrm{C}}{\Theta^{-}}\right) \mathrm{j}=1-\theta / \lambda \mathrm{m} \quad \lambda=\mathrm{R} \Theta^{2} / \mathrm{L}_{0}
\end{aligned}
$$

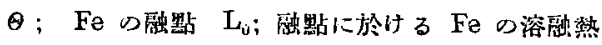

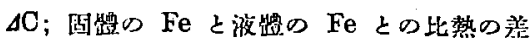

$\mathrm{m} ; \mathrm{Fe} 1000 \mathrm{gr}$ 小に深㑇している C のモル数

こょこ，(1) 式に於ける $\mathrm{m}$ を， Fe-C 系狀態圆に於け

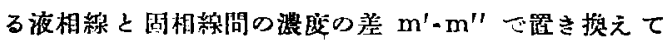

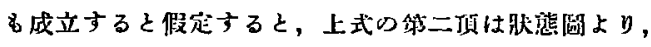

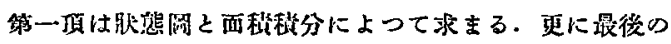
棹分頂は、 $10^{-2}\left(\mathrm{~m}^{\prime}-\mathrm{m}^{\prime \prime}\right)$ 與元られるから，右澳の备 頂は全部きまり， $\boldsymbol{r}^{\prime} か ゙$ 計算される。斯漛にして求めた reは C $1.5 \%$ 过は，砝んどlに近い值を取り、この二 元系は理想溶液之考えられる。

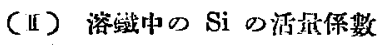

この二元溶液は，Fe 中への $\mathrm{Si}$ の溶僻熱加非常に高 い哥加らを理想溶液とは考えられず，㞣定な化合物が存 在するすの、を考えなければならない.今この溶液を re・ gular solution 飞假定すると, Hildebrand の方法に

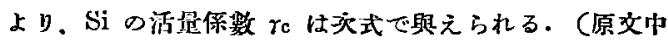
regular solution の宩え方に譟りがある.)

$R T \log \tau_{\mathrm{Si}}=-\left(\mathrm{n}_{1} \mathrm{~V}_{1} / \mathbf{n}_{1} \mathrm{~V}_{1}+\mathrm{n}_{2} \mathrm{~V}_{2}\right)^{2} \mathrm{~V}_{2}$

$$
\left.C_{1} \overline{\mathrm{E}}_{{ }_{\mathrm{Fe}} / \mathrm{T}_{1}}^{-}-\sqrt{\mathrm{E}^{\circ} \mathrm{O}_{\mathrm{Si}} / \bar{V}_{2}}\right)^{2}
$$

$\mathrm{E}^{\circ} \mathrm{Fe}, \mathrm{E}^{\circ}{ }_{\mathrm{Si}} ; \mathrm{Fe}$ 及び $\mathrm{Si}$ の蒸發熟

$\mathrm{n}_{1}, \mathrm{n}_{2} ; \mathrm{Fe}$ Zび Si の.モ几数

$\mathrm{V}_{1}, \mathrm{~V}_{2} ; \mathrm{Fe}$ 改び Si の分子答

rsi $1600^{\circ} \mathrm{C}$ でぼ゙ 0.1 となる. その他溶鐵中の

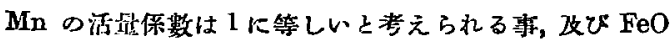

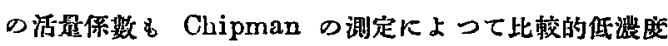

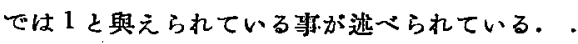

\section{(III) 脆炭反煦}

$\mathrm{FeO}+\mathrm{C} \rightarrow \mathrm{Fe}+\mathrm{CO}$ の本衡恒数 $\mathrm{K}$ を $\mathrm{FeO}+\mathrm{CO} \rightarrow \mathrm{Fe}$ $+\mathrm{CO}_{2} \quad \mathrm{CO}_{2}+\mathrm{C} \rightarrow 2 \mathrm{CO}$ なる二反僬を組合せて求めてい 3.

$$
\begin{gathered}
\log \mathrm{K}=-8570 / \mathrm{T}-2.15 \log \mathrm{T}+0,53 \cdot 10^{-3} \mathrm{~T}- \\
0.16 \cdot 10^{-6} \mathrm{~T}^{2}+14.59
\end{gathered}
$$

更に $\alpha=[\mathrm{FeO}] \times[\mathrm{C}]$ に對しては

$$
\alpha=2880 / \mathrm{K} \times \Sigma_{\mathrm{reO}}
$$

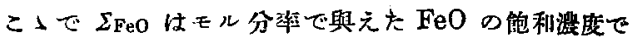
ある.

一括して表に示すと

\begin{tabular}{c|c|c|c|c}
\hline $\begin{array}{c}\text { Tempé- } \\
\text { rature }\end{array}$ & $\mathrm{K}$ & $\Sigma_{\mathrm{FeO}}$ & $\begin{array}{c}\alpha \\
\text { calculé }\end{array}$ & $\begin{array}{c}\alpha \\
\text { mesuré }\end{array}$ \\
\hline 1580 & $2.73 \times 10^{\circ}$ & 0.0092 & 0.0097 & 0.0102 \\
1650 & $3.15 \times 10^{5}$ & 0.0127 & 0.0110 & 0.011 \\
1700 & $3.775 \times 10^{5}$ & 0.016 & 0.0115 & 0.0122 \\
\hline
\end{tabular}

以上 (坂上 六郎)

一鐵及鋼の性質一

\section{大形構造用鍽の熔接性について脆性破壤敏感性}

の看爭 (Walter Grotz, St. u. Ei. 70 (1950) Ht. 26: 1193 1204)

㙌造用銅の脆性の試驗には烙接した試驗片の引張りゃ 屈曲試略で十分であると考えられていたが，斯る方法で は聺接が上手く出來ているかどらかは判定出來る.然し

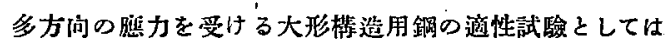

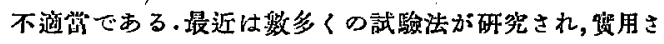
れているが中でも A.B. Kinzel の熔接曲げ武螸，M.

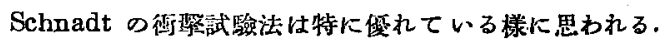
主として之等の試噞法により，平愠銅 St 37, St 52,

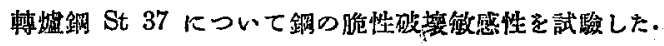
Kinzel 及ど Schnadt の方法によ百試跲結果はいゔれ むよく一政した.

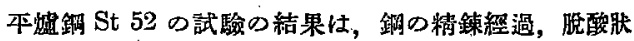
態及び化學組成が良好である場合は脆性破壊に對して敏 感でない孚が碓らられた。. St 52 では俆酸不良のるのは

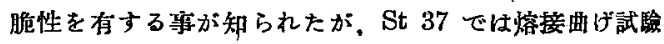
の結果，リムド䞒は综るキルド鋿より優秀な值を示し た・然しリム部の厚さは一定に保つ具が困奞であり，之

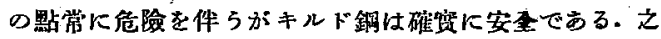
れに對してをミキルドははリムが洗く，脆性破壤を防ぐ 程院酸されていないから本犋的に不利である。トーマス 銅 St 37 について試躁した結果は，普通のトーマス銅，

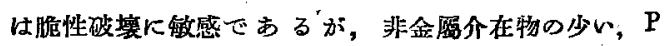
0.05\%>, Al 0.02\%くを含んだキルド銅仕主好結果

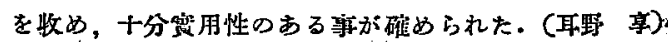

炭素鋼の燒入及び燒戻に對する 電子顯微鏡によ. 了研究 J. Trotter et D. Mclean, J. Iron Steel. Inst. 1949, CLXIII, Part 1, 9 13 


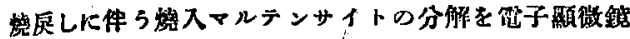
(20,000 倍) を用いて研究した。試料は $0.6 \%$ 炭素鎙

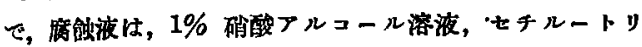
メチルーアムモニウムの臬化物 $0.3 \%$ を含み水で能和 したビクリン酸エーテル溶液, 15〜20\% のクロム酸溶洨

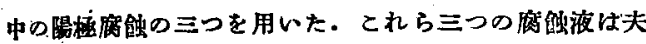
々特微があり，硝酸アルコールは析出物より地を先に磨

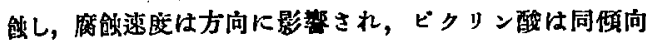
ごあるが，方向性住感でない.クロム酸陽極腐触はマ ルテンサイト結晶粒界を現はし，地よりる析出物を速や

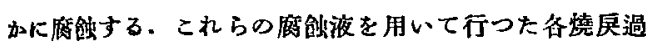

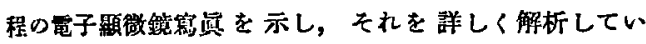
3 .

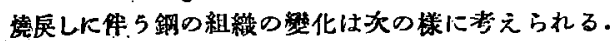
オーステナイトを燃入れると，結晶粒は細かく分裂し， 種々の方向を有する釷い角のマンテンサイト結晶粒を生

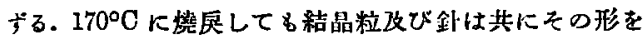

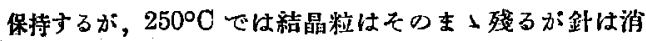
える.細粒の組織が $450^{\circ} \mathrm{C}$ 燒戻しで現はれ，700兄で 住等軸秥晶粒となるが，その大きさは不篎で，晨初のマ ルテンサイト結昆制より來たるのであることが認められ る. その結晶粒の大さは小さく約 2 ミロンで, 普通の 光學影徽鏡では認められない。

$170^{\circ} \mathrm{C}$ K 1 時間炶厌すことによつて、炭素は 100 400 原子の核とな $り, 250^{\circ} \mathrm{C}$ て $400 \sim 1,000$ 原子の明膫

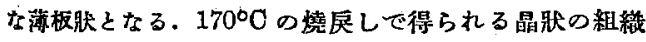
は明睹でない核の生成の隼備段階を示するのでる。 $450^{\circ} \mathrm{C}$ をでば 線的にセメンタイトの存在は認められ ナ゙, 及 250〜450 $\mathrm{C}$ でこの溥板狀の部分がなくなるの 亡これはセメンタイトでない相を形成しているるのと 想你し得る.(牧野 第)

路及び金の時奻現象 J. D. Fast, Revue de Métallurgie, 47 (1950), 10. 779 786

少量の他元素を含む工業用载銅特に軟銅に於ては，燒 入後丈は加工後に不安定な狀悲を有し，常盜又はてれ上 り稍中高い溫度に放置すると，硬度が上昇し鞇性が減少

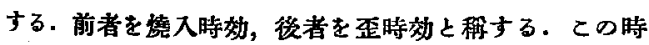

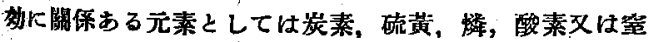
菜があげられているが，未だ明確なる結果が得られてい ない，著者はえ等諸元素の時㭁に對する影警を別々に單

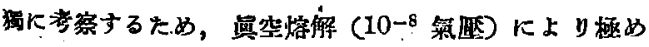

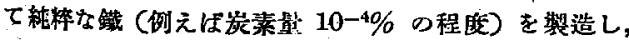
これに一文はそれ以上の元素を添加して，ヴィカース硬

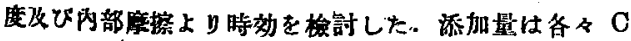

$0.04 \%, \mathrm{O}_{2} 0.03 \%, \mathrm{~N}_{2} 0.02 \%$ であり, 及これに更に

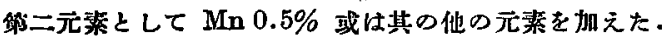

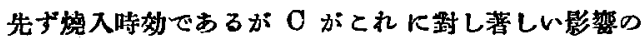
あるととは從來加ら認められていたが， $\mathrm{N}_{2}$ る又著しく 時効を促進するととが制つた。然し $\mathrm{O}_{2}$ は绐んど效果な い. Mn の存在は $\mathrm{C}$ を含む錒の時奻には却つて助長す る㑯向あるが， $\mathrm{N}_{2}$ に上る時効が殆んど無くなつてしま 5點は注目に僄する。

次に昰洔效に對しては $\mathrm{O}_{2}$ が大きな影暨を有すると從

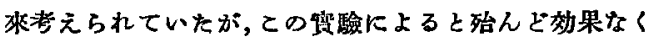
しかも C，Mn 又は Si を含丸でいると酸素溶解度は減 るので一届少なくなる。著者によると柾時効の主要な原 因は咥素であると言 5. $\mathrm{N}_{2} 0.001 \%$ 程度であつて\&， 又 Mn が存在していても最大の時奻を得るに十分であ る. C は常溫の雪時効の存在を促進しないか，少し温度

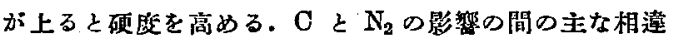
は溶排底の相连に上る。(牧野昇)

\section{工具鎆の硬度に對する燒戻し時間の影響}

Anton Pomp, Alfred Krisch, Archiv Eisenhüttenw 20 (1949) 7 8, 255 62

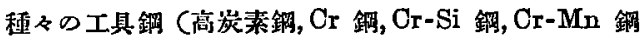

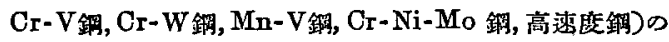

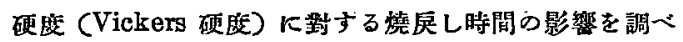

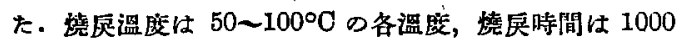
時間までである，同じ試片で硬度が可成りばらつくこと がある (場合によつては 50〜100 程度).てれは軟點の

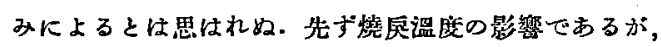
炶居時間を 1 分程鹿に取つてむ既に乾化は認められる。 しかし洔間の正確を期することは難しいので，1時間を 取つた。その硬度一温度曲線を圆示してあるが，初硬度 としては試料のばらつきをふせぐため $50^{\circ} \mathrm{C}$ 笑戻しの值

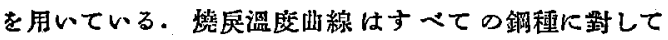
$90^{\circ} \mathrm{C}$ 以上では硬度が連校的に低下して行くが，120 附近及び $210 \sim 240^{\circ} \mathrm{C}$ で硬度上昇の認められる㻛合があ る. 硬店の低下は最初の 1 時間が大きくその後は少な い.次に 1 時間燒庆しを行つた陚料を用いて，蟯戻し時 間の硬度に及居す影製を調へた。それによると時間に保 ラ硬度低下の最る著しいのは $120 \sim 150^{\circ} \mathrm{C}$ の溫度である のは注目すでき點である。乙の時間曲線の形は次の式に より表わされる。

$$
\mathrm{H}_{1}-\mathrm{H}_{2}=\mathrm{A} \log (\mathrm{Z}-1)+\mathrm{C}
$$

$\mathrm{H}_{1}, \mathrm{H}_{2}$ は 1 時間及び $\mathrm{Z}$ 時間後の硬度，A， $\mathrm{C}$ は常 数. A は $120 \sim 150^{\circ} \mathrm{C}$ 附近が最大で, $180 \sim 210^{\circ} \mathrm{C}$ 附近 が最小であつた。(牧野 昇) 


\section{一雜一}

弗化物の治金反㕍 H. H. Kellogg; Journal of metals 191 (1951) 2, 137

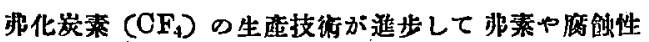
弗化物の整造コストの下つたととがよく知られている。 メタルの抽出に非素法が單筫を切り下びる上に見過せな い力をるつているとのため非化物の自由ェネルキーを 表及び圆に示し，引用交㮝をあげた. $1000^{\circ} \mathrm{C}$ K和いて $\pm 1 \mathrm{Kcal}$ の諤差はさけがたく，お石るのは $\pm 3 \mathrm{Kcal}$

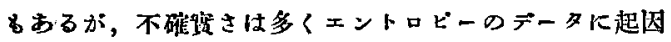
$す る$.

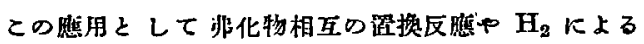

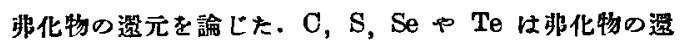
元劑に適しないか， $\mathrm{Mg}$ は $\mathrm{TiF}_{4}, \mathrm{ZrF}_{4}, \mathrm{SiF}_{4}$ 還元で

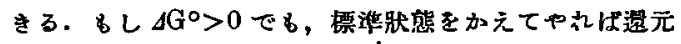
可能になる。例元ば

$$
\begin{gathered}
1 / 2 \mathrm{Si}(\mathrm{s})+2 / 3 \mathrm{AlF}_{3}(\mathrm{~s})=2 / 3 \mathrm{Al}(\mathrm{l})+1 / 2 \mathrm{SiF}_{4}(\mathrm{~g}) \\
\Delta \mathrm{G}^{\circ}=3,000 \mathrm{cal}
\end{gathered}
$$

$$
\begin{aligned}
& \mathrm{K} 700^{\circ} \mathrm{O}=0.212 \\
& \mathrm{p}_{\mathrm{Sir}} \approx 0.045 \mathrm{~atm}=34 \mathrm{~mm} \mathrm{Hg}
\end{aligned}
$$

故にざつと言って $34 \mathrm{~mm} \mathrm{Hg}$ 以下で操作すればよい，

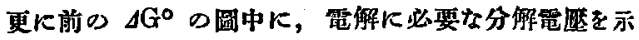
した. $3 \mathrm{NaF} ・ \mathrm{AJF}_{3}$ の5な被弗化物のできる時は，そ の安定度に比例して，個くの非化物の活量を下げる。次

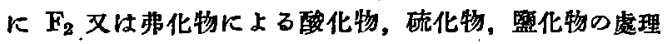
を逝でた。

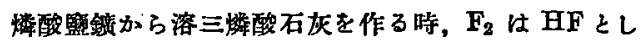
て逃げるのであるが，林の $\mathrm{CaCO}_{3}$ と反愿して回收で ?る.

$$
\begin{gathered}
\mathrm{CaCO}_{3}+2 \mathrm{HF}=\mathrm{CaF}_{2}+\mathrm{H}_{2} \mathrm{O}+\mathrm{CO}_{2} \\
\Delta \mathrm{G}_{250^{\circ} \mathrm{C}}=-28,100 \mathrm{cal}<0
\end{gathered}
$$

更に高次の粼酸石灰ならば $\mathrm{F}_{2}$ は $\mathrm{SiF}_{4}$ Кなつている が，六式によつて捕えることがでる。

$$
\begin{gathered}
\mathrm{CaCO}_{3}+1 / 2 \mathrm{SiF}_{4}(\mathrm{~g})=1 / 2 \mathrm{SiO}_{2}+\mathrm{CaF}_{2}+\mathrm{CO}_{2}(\mathrm{~g}) \\
\Delta \mathrm{G}_{20^{\circ} \mathrm{C}}=-20,200 \mathrm{cal}<0
\end{gathered}
$$

(松下 幸雄)

(47 而よりつら゙く)

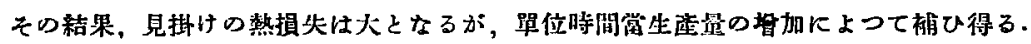

(a) 旸口の調整

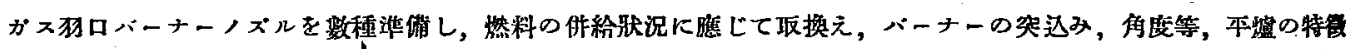

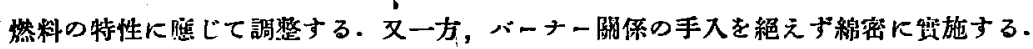

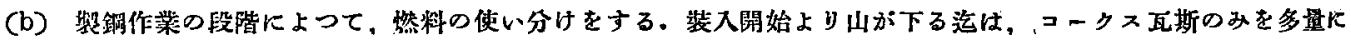

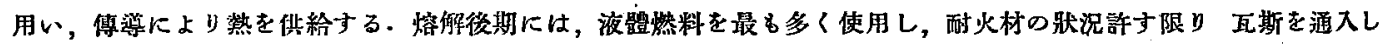

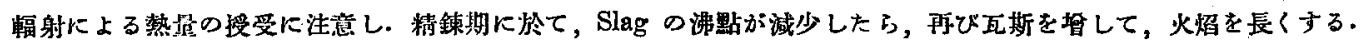

(c) 第一㳄空氯の庭力を極力高くする。

$$
\text { 一以下次跳元䖻く - }
$$

